\title{
Farklı adeziv sistemler uygulanarak yerleştirilen fissür örtücülerin 6 aylık klinik takibi: randomize kontrollü çalışma
}

\author{
Emel Karaman, ${ }^{1 *}$ Emine Özdemir Taştan, ${ }^{2}$ Eda Güler ${ }^{1}$ \\ ${ }^{1}$ Restoratif Diş Tedavisi Anabilim Dalı, Ondokuz Mayıs \\ Üniversitesi Diş Hekimliği Fakültesi, Samsun, ${ }^{2}$ Restoratif Diş \\ Tedavisi Anabilim Dalı, Gaziosmanpaşa Üniversitesi \\ Diş Hekimliği Fakültesi, Tokat, Türkiye
}

\section{Özet}

AmAÇ: Bu çalışmada, pürüzlendirip yıkamalı (etch\&rinse) adeziv sistem (Adper Single Bond 2 ) ve hem kendinden pürüzlendirmeli (self-etch) hem de pürüzlendirip yıkamalı olarak kullanılabilen bir adeziv sistem (Single Bond Universal) kullanılarak uygulanan fissür örtücülerin retansiyon ve çürük oluşumu açısından 6 aylık sonuçlarının değerlendirilmesi amaçlanmıştır.

GEREÇ VE YöNTEM: Bu klinik çalışmada yaşları 19-22 arasında değişen, 13 bireye uygulanan non-invaziv fissür örtücüler değerlendirildi. Dişler plaktan temizlendikten sonra fissür örtücü Fissurit FX (Voco, Cuxhaven, Almanya), rastgele sayılar tablosu yardımıyla Grup A: \%35 fosforik asit + Adper Single Bond 2 (3M ESPE, St Paul MN, ABD), Grup B: \%35 fosforik asit + Single Bond Universal adeziv (3M ESPE, St Paul MN, ABD), Grup C: Single Bond Universal adeziv uygulandıktan sonra tek bir hekim tarafından yerleştirildi ve polimerize edildi. Tüm materyaller üretici firmanın önerileri doğrultusunda kullanıldı. Her bir grupta $\mathbf{4 8}$ adet olacak şekilde, toplamda 144 dişe fissür örtücü uygulandı. Fissür örtücülerin retansiyonu ve çürük oluşumu birbirleriyle kalibre iki hekim tarafından 1 hafta ve 6 ay sonra reflektör ışığı altında, ayna ve sond yardımıyla değerlendirildi. Fissür örtücülerin değerlendirilme kriterleri: 1=tam retansiyon, 2=kısmi kayıp, 3=total kayıp şeklinde idi. Elde edilen veriler Pearson ki-kare testi ile analiz edildi.

BULGULAR: Çalışmaya dahil edilen tüm bireyler 6. ay kontrolüne geldi. A grubunda uygulanan 48 fissür örtücünün \%93.75'i tam retansiyon, \%6.25'i total kayıp olarak değerlendirildi. B grubunda ise fissür örtücülerin tamamında tam retansiyon gözlendi. C grubunda uygulanan fissür örtücülerde \%29.2 tam retansiyon, \%68.8 tam kayıp, \%2.1 kısmi kayıp gözlendi ve bu grupta retansiyon oranları diğer gruplardan istatistiksel olarak anlamlı düzeyde düşük bu-

Makale gönderiliş tarihi: 09 Aralık 2014; Yayına kabul tarihi: 22 Ocak 2015 *iletişim: Emel Karaman, Ondokuz Mayıs Üniversitesi Diş Hekimliği Fakültesi, Restoratif Diş Tedavisi AD, Samsun, Türkiye;

e-posta: dtemelc@yahoo.com lundu ( $p<0.001)$.Grupların hiçbirinde çürük oluşumuna rastlanmadı.

Sonuç: Single Bond Universal adezivin kendinden pürüzlendirmeli olarak uygulandığı grupta daha düşük klinik performans gözlendi

Anahtar Kelimeler: Dental adezivler; diş çürükleri; fissür örtücüler

Kaynak Göstermek İçin: Karaman E, Özdemir Taştan E, Güler E. Farklı adeziv sistemler uygulanarak yerleştirilen fissür örtücülerin 6 aylık klinik takibi: randomize kontrollü çalışma. Acta Odontol Turc 2015;32(3):106-11.

YAYIN HAKKI: @ 2015 Karaman ve ark. Bu eserin yayın hakkı Creative Commons Attribution License ile ruhsatlandırılmıştır. Sınırsız kullanım, dağıtım ve her türlü ortamda çoğaltım, yazarlar ve kaynağın belirtilmesi kaydıyla serbesttir.

[Abstract in English is at the end of the manuscript]

\section{Giriş}

Son yıllarda modern diş hekimliğinin ilgi alanı, çürük riskini azaltmak amacıyla koruyucu uygulamaların yapılması ve diş yapılarının mümkün olduğunca korunduğu non-invaziv konservatif tekniklerin gelişmesi olmuştur. Buna bağlı olarak günümüzde çürük prevalansı azalmış, biçim ve ilerleme hızı bakımından değişikliğe uğramıştır. ${ }^{1,2}$

Dişlerin çiğneyici yüzeyleri üzerindeki pit ve fissürler diş çürüğü açısından riskli anatomik oluşumlardır. Pit ve fissürler toplam diş yüzeylerinin sadece \%12.5 kısmını oluşturmaktadır. Ancak karmaşık morfolojilerine bağlı olarak oklüzal pit ve fissürler, çürük gelişimine en fazla eğilim gösteren alanlar olup çürükten etkilenen diş yüzeylerinin \%85'inden fazlasını oluşturmaktadır. ${ }^{3-6}$ Fissür örtücü ile pit ve fissürlerin kapatılması ile bakteriler için gerekli olan beslenme kaynağı elimine edilir ve böylece çürüğün ilerlemesi durdurulmuş olur. ${ }^{7}$ Fissür örtücü uygulamaları oklüzal yüzeylerdeki çürüğün önlenmesinde etkinliği kanıtlanmış bir yaklaşımdır. ${ }^{2,8}$ Bu uygulama, oklüzal diş yüzeylerinin pit ve fissürlerinde çürük oluşumunu önlemek için 30 yılı aşkın süredir kullanılmaktadır. ${ }^{8,9}$

Yapılan çalışmalarda invaziv tekniklerle yapılan fissür örtücülerin mekanik preparasyonun ardından örtücü retansiyon oranının arttığı ve mikrosızıntı riskinin azal- 
dığı bildirilmiştir. ${ }^{10-12}$ Bununla beraber, non-invaziv tekniklerle uygulanan örtücülerin pit ve fissür çürüklerini önlemede son derece etkili olduğu bildirilmiştir ve birçok klinik çalışmada retansiyonu ve etkinliği gösterilmiştir.9,13

Fissür örtücülerin koruyucu etki sağlamasındaki başarısı, materyal ile mine arasındaki adezyonun kalitesine ve buna bağlı olarak uzun dönem retansiyonuna bağlıdır. ${ }^{14}$ Bu retansiyon, çalışılan dişin izolasyonuna, kullanılan materyalin viskozitesine, mine yüzeyinin hazırlanmasına ve adeziv sisteme bağlı olarak değişebilmektedir. ${ }^{15}$

Dişlerin çiğneyici yüzeyindeki mine dokusunun asitle pürüzlendirilmesi pit ve fissür örtücülerin uygulanmasındaki ilk basamaktır. Bu işlem 1965 yılından beri standart olarak kullanılmaktadır. ${ }^{16}$ Geleneksel olarak çeşitli yoğunluktaki fosforik asit ile mineye ön uygulama yapılması, fissür örtücü materyalinin retansiyonunu sağlayan mikropörözitelerin oluşturulmasını sağlar. Ayrıca fosforik asit ön uygulaması minenin ıslanabilirliğini arttırmakta ve antibakteriyel etki sağlamaktadır. ${ }^{17}$

Ancak geleneksel pürüzlendirip yıkamalı (etch\&rinse) sistemlerde dentin kollajenleri arasında kalan fazla su nedeniyle bağlantı problemi oluşmaktadır. ${ }^{18,19} \mathrm{Bu}$ dezavantajı ortadan kaldırmak amacıyla kendinden pürüzlendirmeli (self-etch) adezivler geliştirilmiştir. Ancak kendinden pürüzlendirmeli adezivler mineyi fosforik asit kadar dağlayamazlar ve düşük mine bağlanması sonucunda klinik olarak sık karşılaşılan bir durum olan restorasyon kenarlarında kopmalar meydana gelir. ${ }^{20}$

Son zamanlarda klinik kulanım kolaylığı sunan tek aşamalı kendinden pürüzlendirmeli adezivlerin dezavantajlarını ortadan kaldırmaya yönelik çalışmalar sonucu 'Universal' veya 'Multimod' olarak isimlendirilen ürünler ortaya çıkmıştır. ${ }^{21,22}$ Bu ürünler hem kendinden pürüzlendirmeli hem de pürüzlendirip yıkamalı olarak kullanılabilirler ve kendilerine has bir yapıya sahip oldukları için bağlantı çalışmalarında sıklıkla kullanılmaktadır. ${ }^{23}$

Adeziv sistemler genellikle in vitro olarak test edilmektedir; ancak in vitro çalışmaların kısıtlamaları mevcuttur ve bu nedenle adeziv sistemleri oral kavitede değerlendiren klinik çalışmalara intiyaç vardır.

Bu klinik çalışmada, bir pürüzlendirip yıkamalı sistem ve hem kendinden pürüzlendirmeli hem de pürüzlendirip yıkamalı olarak kullanılan bir üniversal adeziv sistemin, uygulanan fissür örtücülerin klinik başarısına olan etkilerinin 6 ay süresince karşılaştırılması amaçlanmıştır.

\section{Gereç Ve Yöntem}

\section{Çalışma grubunun belirlenmesi}

Çalışmaya Ondokuz Mayıs Üniversitesi Diş Hekimliği Fakültesi Restoratif Diş Tedavisi Kliniğine başvuran, yaşları 19-22 arasında değişen, herhangi bir sistemik rahatsızlığı olmayan, ağız hijyeni iyi, yapılan intraoral muayenede en az üç adet derin ve dar pit ve fissürlere sahip, tam sürmüş daimi premolar ve molar dişleri olan 13 birey dahil edildi. Bu randomize kontrollü klinik çalışma, Ondokuz Mayıs Üniversitesi Tıp Fakültesi Tıbbi Araştırmalar Etik Kurulu tarafından onaylandı. Çalışmaya katılan bireyler çalışma konusunda bilgilendirildikten sonra yazılı onam formları imzalatıldı. Çalışmaya başlamadan önce kuvvet analizi yapılarak gruplar arasında pre-post skoru değişimi bakımından en az 0.2 birim fark olacağı öngörüldü. Buna göre 0.80 kuvvet ve 0.05 tip I hata düzeylerinde, gruplara en az 46 diş bulunması gerektiği sonucuna varıldı.

\section{Fissür örtücülerin uygulanması}

İşlem öncesinde diş yüzeyindeki plak ve organik artıklar beyaz lastikler ile uzaklaştırıldı ve tüm yüzeyler hava-su spreyi yardımıyla temizlendi. Fissür örtücüler rastgele sayılar tablosuna göre 3 farklı gruba ayrılarak uygulandı. Grup A ve B'de dişlerin fissürleri \%35 fosforik asit (Scotchbond, 3M ESPE) ile 30 sn pürüzlendirildi, 15 sn su ile yıkandı, tebeşirimsi beyaz görüntü elde edilene kadar hava-su spreyi ile kurutuldu. Grup A'da bir pürüzlendirip yıkamalı adeziv olan Adper Single Bond 2 (3M ESPE), Grup B'de ise üniversal bir adeziv olan Single Bond Universal adeziv (3M ESPE, St. Paul MN, ABD) uygulanıp LED ışık kaynağı ile10 sn polimerize edildi (Elipar Freelight 2, 3M ESPE). Grup C'de, fissürler hava-su spreyi ile kurutulup, Single Bond Universal Adeziv (3M ESPE) uygulandı ve LED ışık kaynağı ile 10 sn polimerize edildi (Tablo 1). Tüm dişlere fissür örtücü olarak Fissurit FX (Voco, Cuxhaven, Almanya) fissürlerin tamamını örtecek şekilde uygulandı. Dişler sond yardımıyla kontrol edildi ve diş üzerinde eksik ya da hava kabarcığı olan bölgeler varsa işlem tekrarlandı ve 20 sn polimerize edildi. Çalışmada kullanılan tüm materyaller üretici firmanın önerileri doğrultusunda uygulandı. Polimerizasyon sonrasında artikülasyon kâğıdı ile oklüzyon kontrolü yapıldı ve ince grenli elmas frezler (Diatech, Swiss Dental, Heerbrugg, İsviçre) ve polisaj lastikleri (Edenta AG, St Gallen, İsviçre) ile su soğutması altında bitirme ve polisaj işlemleri tamamlandı. Maksiller ve mandibüler, sağ ve sol olmak üzere 85 küçük azı ve 59 büyük azı, toplam 144 dişe fissür örtücü uygulandı (Tablo 2).

Bütün bireylerin tedavisi aynı araştırmacı tarafından yapıldı ve bireyler 1 hafta ve 6 ay sonra tekrar kontrole çağrıldı. Yapılmış olan fissür örtücüler, Ondokuz Mayıs Üniversitesi Diş Hekimliği Fakültesi, Restoratif Diş Tedavisi Anabilim Dalı'nda görevli, uygulanan tedavilerden habersiz, kalibre iki farklı hekim tarafından, uygun bir reflektör ışığı altında, ayna ve sond yardımıyla değerlendirildi. Fissür örtücülerin değerlendirilme kriterleri: 
Tablo 1. Çalışmada kullanılan materyaller

\begin{tabular}{|c|c|c|}
\hline Materyal & iç̧erik & Üretici firma \\
\hline Adper Single Bond 2 & $\begin{array}{l}\text { HEMA, bis-GMA, dimetakrilatlar, metakrilat, fonksiyonel kopolimer (poliakrilik asit ve } \\
\text { poli-itakonik asit), foto başlatıcılar, etanol, su }\end{array}$ & 3M ESPE, St Paul, MN, ABD \\
\hline Single Bond Universal Adeziv & $\begin{array}{l}\text { MDP fosfat monomer, dimetakrilatlar, HEMA, Vitrebond }{ }^{\mathrm{TM}} \text { kopolimeri, doldurucular, } \\
\text { etanol, su, başlatıcılar, silan }\end{array}$ & 3M ESPE, St. Paul, MN, ABD \\
\hline Fissurit FX & $\% 55$ oranında inorganik ve cam iyonomer doldurucu (maksimum $10 \mu \mathrm{m}$ ), bis-GMA, $\% 2 \mathrm{NaF}$ & Voco, Cuxhaven, Almanya \\
\hline
\end{tabular}

Tablo 2. Uygulanan adeziv sistemlerin dişlere göre dağılımı

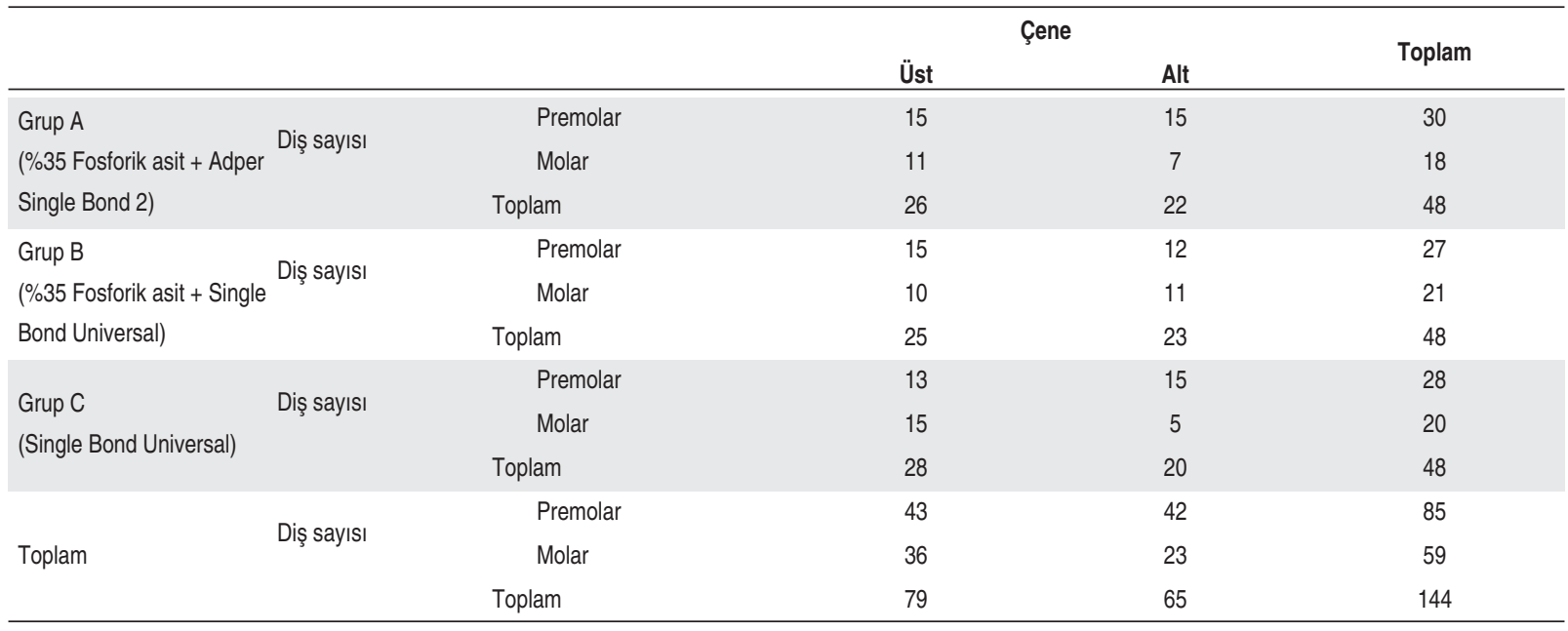

Tablo 3. Fissür örtücülerin retansiyon oranları

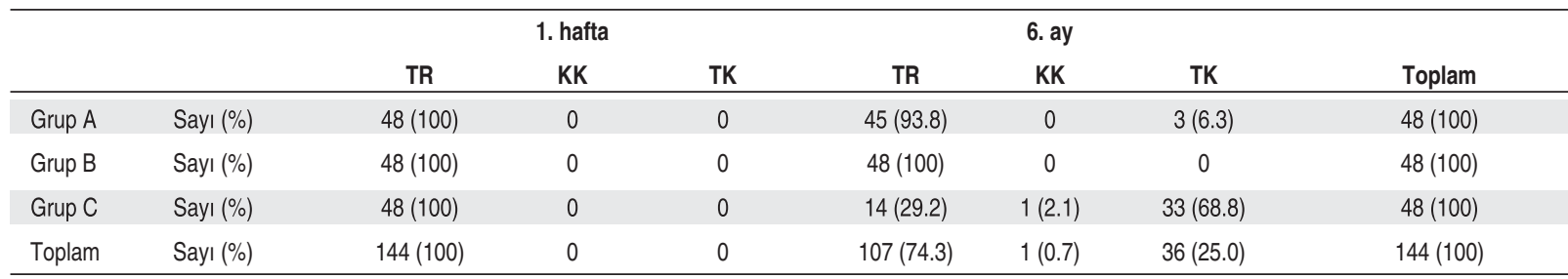

TR: Tam retansiyon, KK: Kısmi kayıp, TK: Tam kayıp

1=tam retansiyon, 2=kısmi kayıp, 3=total kayıp şeklinde idi. Dişlerde çürük oluşumu 'çürük var' veya 'çürük yok' şeklinde değerlendirildi. Değerlendirme ile ilgili herhangi bir anlaşmazlık olduğunda, değerlendirme tekrarlandı ve ortak bir karara varıldı.

\section{İstatistiksel analiz}

Elde edilen veriler Pearson ki-kare testi kullanılarak analiz edildi. İstatistiksel anlamlılık seviyesi $p<0.05$ olarak kabul edildi.

\section{BULGULAR}

Çalışmaya dahil edilen tüm bireyler 1. hafta ve 6. ay kontrolüne geldi. Grupların 1. hafta ve 6 ay sonundaki retansiyon oranları Tablo 3'te ayrıntılı bir şekilde verildi. 1.hafta kontrolünde uygulanan fissür örtücülerin hiçbirinde kısmi ya da tam kayba rastlanmadı.
6 ay kontrolünde A grubunda yapılan 48 fissür örtücünün $\% 93.75$ 'i tam retansiyon, $\% 6,25$ 'i total kayıp olarak değerlendirildi. B grubunda ise 48 fissür örtücünün tamamında tam retansiyon gözlendi, herhangi bir kısmi veya tam kayıp gözlenmedi. Single Bond Universal adezivin kendinden pürüzlendirmeli olarak uygulandığı C grubunda ise, yapılan fissür örtücülerde \%29.2 tam retansiyon, \%68.8 tam kayıp, \%2.1 kısmi kayıp gözlendi. C Grubu, diğer gruplardan istatistiksel olarak anlamlı düzeyde düşük retansiyon gösterirken $(p<0.001)$, $A$ ve $B$ gruplarının retansiyon oranları istatistiksel olarak birbirine benzer bulundu. Fissür örtücü uygulanan dişlerin hiçbirinde çürük oluşumuna rastlanmadı.

\section{TARTIŞMA}

Dişlerin oklüzal pit ve fissürleri, ağız-diş sağlığını etkileyen hastalıkların en önemli kısmını oluşturan diş çürük- 
lerinden en çok etkilenen bölgelerdir. Karmaşık morfolojisi nedeniyle bakteriyel yığılma ve proliferasyona neden olan büyük ve küçük azı dişlerinin oklüzal yüzeyleri, çürük lezyonlarının \%60-85'inden sorumlu tutulmaktadır. ${ }^{3,4}$ Oklüzal yüzeylerdeki bu çürük oluşumunu önlemek amacıyla ağrısız ve konservatif bir yöntem olan pit ve fissür örtücü uygulamalarının yapılması önerilmektedir. ${ }^{8,14}$

Black, dişler üzerindeki pit ve fissürleri yüzey defekti olarak kabul etmiş ve bu yüzey defektlerinin çürüğe neden olan bakterilerin penetrasyonuna sebep olduğunu öne sürmüştür. Bu yüzden, okluzal pit ve fissürlerin düz yüzeyler haline getirilmesi ile mikroorganizmaların yerleşimi ve dolayısıyla çürük gelişiminin önlenebileceği düşünülmektedir. Günümüzde de pit ve fissürlerin, bakteriyel plağın ve mikroorganizmaların yerleşim bölgesi olduğu kabul edilmiştir. Bu nedenle çürük oluşumuna eğilimli olan dişlerin pit ve fissürlerinin ağız ortamından izole edilmesi amacıyla fissür örtücü uygulaması yaygın olarak kullanımaktadır ve bu uygulama ile çürük yapıcı mikroorganizmalar pit ve fissürlere yerleşememektedir. ${ }^{24-26}$

Fissür örtücü ilk kez 1965 yılında uygulanmıştır. Daha sonra yapılan çok sayıda klinik ve laboratuvar çaIışmalarla, fissür örtücü uygulamasının güvenli ve etkili bir çürük önleme yöntemi olduğu gösterilmiştir. American Dental Association (ADA), 1970'lerin başında fissür örtücü tedavilerinin etkinliğini kabul etmiştir. ${ }^{27}$

Fissür örtücü uygulanmasından önce asitle pürüzlendirme yapılması, mine üzerindeki eklentileri uzaklaştırıp, düzensiz, mikropöröz bir yapı oluşturduğu için sıklıkla önerilmektedir. Bir fissür örtücünün başarısını etkileyen birincil faktör, mineye gösterdiği marjinal adaptasyondur. ${ }^{28}$ Bununla birlikte asidin hoş olmayan tadı, yıkama ve kurutma esnasında karşılaşılabilecek sorunlar, hastalar ve hekimler açısından zorlayıcı olabilmektedir. Kendinden pürüzlendirmeli sistemler, pürüzlendirip yıkamalı sitemlerde karşılaşılan bu sorunların önüne geçmek, adeziv uygulanmasının teknik hassasiyetini azaltmak ve uygulama süresini kısaltmak üzere piyasaya sürülmüş ürünlerdir. Ancak bu sistemlerin mine dokusuyla kurdukları bağlantının zayıf olduğu ve bu nedenle uygulanan restorasyonlarda başarısızlıkla karşılaşılabileceği bildirilmiştir. ${ }^{20}$ Mine dokusuyla olan bu zayıf bağlantıyı güçlendirebilmek için kendinden pürüzlendirmeli sistemler uygulanmadan önce mine kenarlarının selektif olarak fosforik asit ile pürüzlendirilmesi önerilmektedir. ${ }^{29}$ Ancak bu uygulama klinik koşullarda pek kolay olmamakta, hekimler asidi dentin dokusuna taşırmadan yalnızca mine dokusuna uygulamakta zorluk çekmektedirler. Kendinden pürüzlendirmeli adezivlerin bu dezavantajlarını ortadan kaldırmak amacıyla 'universal' ya da 'multimod' olarak adlandırılan adeziv sistemler piyasaya sürülmüştür. Bu yeni sistem sayesinde hekim, tek bir adeziv ile, hazırladığı kaviteye ve uygulayacağı restorasyona en uygun olan adeziv uygulamasına karar verme şansına sahip olmaktadır.

Fissür örtücü retansiyonuyla ilgili yapılan en uzun klinik takip çalışmasında, fissür örtücü sadece 1 kez uygulanan dişlerin 5 yıl sonunda \%82 sinde, 10 yıl sonunda \%57'sinde, 15 yıl sonunda \%28'inde çürüğe rastlanmamıştır. ${ }^{14}$ Çalışmalar bu uzun süreç içinde fissür örtücülerin gerekli kontrolleri yapılırsa ve gerektiinde yeniden uygulanırsa çürük sayısının daha az düzeylerde kalabileceğini göstermiştir. ${ }^{30}$ Bizim çalışmamızda da fissür örtücü uygulanan dişlerin hiçbirinde çürüğe rastlanmamıştır.

Bu çalışmada kendinden pürüzlendirmeli ve pürüzlendirip yıkamalı olarak kullanılabilen modern bir adeziv olan Single Bond Universal'in mineye asit uygulanarak ve uygulanmayarak retansiyon değerleri 6 ay süresince incelenmiştir. Kontrol grubunda ise, bir pürüzlendirip yıkamalı adeziv sistem olan Adper Single Bond 2 kullanılmıştır. Fissür örtücülerin retansiyonları açısından en kritik sürecin uygulamadan sonraki ilk 6 ay olduğu bildirildiğinden, 6 aylık sonuçların değerlendirilmesine karar verilmiştir. ${ }^{31}$ Çalışmanın bulguları kendinden pürüzlendirmeli olarak uygulanan üniversal adeziv kullanılarak yerleştirilen fissür örtücülerin retansiyonunun diğer gruplardan daha düşük olduğunu göstermiştir. Beloica ve ark. $^{32}$ işlem uygulanmamış mineye tek aşamalı bir kendinden pürüzlendirmeli adezivin mikro makaslama ve mikro gerilim bağlanma kuvvetinin, pürüzlendirip yıkamalı adezivden anlamlı düzeyde daha düşük olduğunu bildirmiştir. Ayrıca kendinden pürüzlendirmeli adeziv uygulaması öncesinde mine yüzeyinin fosforik asit ile pürüzlendirilmesinin olumlu etkilerini ve mineye olan bağlantı değerlerini arttırdığını gösteren birçok çalışma mevcuttur. ${ }^{33-35}$

Bu çalışmanın bulgularıyla uyumlu olarak Venker ve ark. $^{36} 12$ aylık klinik çalışmalarının sonucunda, fosforik asitle pürüzlendirme sonrası uygulanan fissür örtücülerin, kendinden pürüzlendirmeli adeziv sistem ile uygulanan fissür örtücülerden daha yüksek retansiyon oranları gösterdiğini bildirmişlerdir. Başka bir klinik çalışmada da, benzer şekilde kendinden pürüzlendirmeli sistem ile uygulanan fissür örtücülerin retansiyonunun, pürüzlendirip yıkamalı sistem ile uygulanan fissür örtücülerden daha düşük olduğu, fissür örtücü uygulaması öncesinde minenin fosforik asitle pürüzlendirilmesinin en uygun yöntem olduğu bildirilmiştir. ${ }^{37}$

Çalışmamızda fissür örtücü uygulaması öncesinde fosforik asit uygulanan grupların retansiyon oranları arasında istatistiksel olarak anlamlı bir farklılık çıkmamakla birlikte, Single Bond 2 uygulanan grupta fissür örtücülerin \%6.25'i tam kayıp olarak kaydedilirken, Single Bond Universal adeziv kullanılan grupta tüm fissür örtücülerde tam retansiyon gözlenmiştir. Bu durum Single Bond Uni- 
versal adeziv sistemin içeriğinde dimetakrilat monomerler yerine 10-metakriloloksidesil dihidrojen fosfat (MDP) monomeri yer almasıyla ilişkili olabilir. Yapılan çalışmalarda, 10-MDP monomer varlığında mine ve dentin dokusuyla stabil, kimyasal bir bağlantının oluştuğu ve 10-MDP monomerinin dayanıkı bir ara yüz elde edilmesinde önemli bir rol oynadığı belirtilmiştir. ${ }^{29,38}$

Single Bond Universal adeziv, ayrıca yapısında polialkenoik asit kopolimeri içermektedir. Bu kopolimerin hidroksiapatitte bulunan kalsiyum ile kimyasal olarak bağlandığı belirtilmiştir. ${ }^{39}$ Kendinden pürüzlendirmeli adezivler içerisindeki polialkenoik asit kopolimeri gibi polikarboksilik monomerler ile hidroksiapatit arasındaki kimyasal bağlanmanın da çok önemli olduğu, karboksil gruplarının, fosfat iyonları ile yer değiştirerek kalsiyum ile iyonik bağ yaparak hidroksiapatit ile bağlanabildikleri bildirilmiştir. ${ }^{40}$

Literatür incelendiğinde üniversal adeziv sistemler kullanılarak yapılmış çok az sayıda in vivo çalışmaya rastlanmaktadır. Bu çalışmalardan biri Mena-Serrano ve arkadaşlarının ${ }^{41}$ çürüksüz servikal lezyonlara üniversal bağlayıcı ajanı farkı adeziv tekniklerle uyguladıkları restorasyonları, klinik koşullarda 6 ay boyunca değerlendirdikleri çalışmalarıdır ki, bu çalışmada klinik olarak bağlayıcı ajanın selektif-etch, kendinden pürüzlendirmeli veya pürüzlendirip yıkamalı olarak kullanımlarında fark bulamamışlardır. Araştırmacılar üniversal adeziv sistemin çürüksüz servikal lezyonların restorasyonunda kullanılabilir olduğunu bildirmişlerdir. Ancak bu çalışmada restorasyonlar, bizim çalışmamızdan farklı olarak çürüksüz servikal lezyonlara uygulandığından, bulgular bizim çalışmamızın bulgularıyla doğrudan karşılaştııılamamaktadır. Çalışmamızın bulgularının desteklenebilmesi için çok sayıda in vitro ve in vivo çalışmaya intiyaç vardır. Ayrıca fissür örtücülerin klinik performanslarının değerlendirilebilmesi için 6 aylık klinik takip süresi yeterli olmadığından bu randomize klinik çalışmanın 12 ve 24. ay verilerinin de elde edilmesi planlanmaktadır.

\section{Sonuç}

Pürüzlendirip yıkamalı olarak kullanılan adeziv sistemler ile uygulanan fissür örtücülerin 6 ay sonunda retansiyon oranları, kendinden pürüzlendirmeli olarak kullanılan universal adeziv sistem ile uygulananlardan daha yüksek bulunmuştur.

\section{TEŞEKKÜR Ve ANMA}

Bu çalışma daha önce 27-28 Ekim 2014 tarihlerinde İstanbul'da gerçekleştirilen Restoratif Diş Hekimliği Derneği, 19. Uluslar arası Bilimsel Kongresi'nde poster olarak sunulmuştur.

Çıkar çatışması: Yazarlar bu çalışmayla ilgili herhangi bir çıkar çatışmalarının bulunmadığını bildirmişılerdir.

\section{KAYNAKLAR}

1. Newbrun E. Preventing dental caries: current and prospective strategies. J Am Dent Assoc 1992;123:68-73.

2. Pardi V, Sinhoreti MA, Pereira AC, Ambrosano GM, Meneghim Mde C. In vitro evaluation of microleakage of different materials used as pitand-fissure sealants. Braz Dent J 2006;17:49-52.

3. Kaste LM, Selwitz RH, Oldakowski RJ, Brunelle JA, Winn DM, Brown LJ. Coronal caries in the primary and permanent dentition of children and adolescents 1-17 years of age: United States, 1988-1991. J Dent Res 1996;75 Spec No:631-41.

4. Hicks MJ, Flaitz CM. Epidemiology of dental caries in the pediatric and adolescent population: a review of past and current trends. J Clin Pediatr Dent 1993;18:43-9.

5. Cehreli SB, Gungor HC, Karabulut E. Er,Cr:YSGG laser pretreatment of primary teeth for bonded fissure sealant application: a quantitative microleakage study. J Adhes Dent 2006;8:381-6.

6. Pereira A, Castellanos R, da Silva S, Watanabe M, Queluz D, Meneghim M. Oral health and periodontal status in Brazilian elderly. Braz Dent J 1996;7:97-102.

7. Matalon S, Slutzky H, Mazor Y, Weiss El. Surface antibacterial properties of fissure sealants. Pediatr Dent 2003;25:43-8.

8. Simonsen RJ. Pit and fissure sealant: review of the literature. Pediatr Dent 2002;24:393-414.

9. Ripa LW. Sealants revisted: an update of the effectiveness of pit-andfissure sealants. Caries Res 1993;27 Suppl 1:77-82.

10. Surmont $P$, Martens $L$, D'Hauwers R. A decision tree for the treatment of caries in posterior teeth. Quintessence Int 1990;21:239-46.

11. Pope BD Jr, Garcia-Godoy F, Summitt JB, Chan DD. Effectiveness of occlusal fissure cleansing methods and sealant micromorphology. ASDC J Dent Child 1996;63:175-80.

12. Garcia-Godoy F, de Araujo FB. Enhancement of fissure sealant penetration and adaptation: the enameloplasty technique. J Clin Pediatr Dent 1994;19:13-8.

13. Mertz-Fairhurst EJ, Adair SM, Sams DR, Curtis JW Jr, Ergle JW, Hawkins Kl, et al. Cariostatic and ultraconservative sealed restorations: nine-year results among children and adults. ASDC J Dent Child 1995;62:97-107.

14. Simonsen RJ. Retention and effectiveness of dental sealant after 15 years. J Am Dent Assoc 1991;122:34-42.

15. Yazici AR, Karaman E, Baseren M, Tuncer D, Yazici E, Unlüer S. Clinical evaluation of a nanofilled fissure sealant placed with different adhesive systems: 24-month results. Oper Dent 2009;34:642-7.

16. Cueto El, Buonocore MG. Sealing of pits and fissures with an adhesive resin: its use in caries prevention. J Am Dent Assoc 1967;75:1218.

17. Burrow MF, Burrow JF, Makinson OF. Pits and fissures: etch resistance in prismless enamel walls. Aust Dent J 2001;46:258-62.

18. Breschi L, Mazzoni A, Ruggeri A, Cadenaro M, Di Lenarda R, De Stefano Dorigo E. Dental adhesion review: aging and stability of the bonded interface. Dent Mater 2008;24:90-101.

19. Sano H. Microtensile testing, nanoleakage, and biodegradation of resin-dentin bonds. J Dent Res 2006;85:11-4.

20. Peumans M, De Munck J, Van Landuyt KL, Poitevin A, Lambrechts $\mathrm{P}$, Van Meerbeek B. Eight-year clinical evaluation of a 2-step self-etch adhesive with and without selective enamel etching. Dent Mater 2010;26:1176-84.

21. Hanabusa M, Mine A, Kuboki T, Momoi Y, Van Ende A, Van Meerbeek $\mathrm{B}$, et al. Bonding effectiveness of a new 'multi-mode' adhesive to enamel and dentine. J Dent 2012;40:475-84.

22. Perdigao J, Sezinando A, Monteiro PC. Laboratory bonding ability of a multi-purpose dentin adhesive. Am J Dent 2012;25:153-8.

23. Barutcugil Ç, Kürklü $D$, Barutcigil $K$, Arslan $\mathrm{H}$. Bond strength of the universal adhesive to dentin with different surface treatments. J Dent Fac Atatürk Uni 2013;21:324-30.

24. Weintraub JA. The effectiveness of pit and fissure sealants. J Public Health Dent 1989;49:317-30. 
25. Gwinnett AJ, Smith DC. Fissure sealants. Smith DC, Williams DF, eds. Biocompatibility of Dental Materials. 1sted. Boca Raton, FL: CRC Press; 1982. p.15-49.

26. Manhart J, Huth KC, Chen HY, Hickel R. Influence of the pretreatment of occlusal pits and fissures on the retention of a fissure sealant. Am J Dent 2004;17:12-8.

27. American Dental Association. Council on Dental Materials and Devices and the Council on Dental Therapeutics: Pit and fissure sealants. J Am Dent Assoc 1976;93:134.

28. Ganesh M, Shobha T. Comparative evaluation of the marginal sealing ability of Fuji VII and Concise as pit and fissure sealants. J Contemp Dent Pract 2007;8:10-8.

29. Erickson RL, Barkmeier WW, Latta MA. The role of etching in bonding to enamel: a comparison of self-etching and etch-and-rinse adhesive systems. Dent Mater 2009;25:1459-67.

30. Pit and fissure sealants. Council on Dental Health and Health Planning. Council on Dental Materials, Instruments, and Equipment. J Am Dent Assoc 1987;114:671-2.

31. Kumaran P. Clinical evaluation of the retention of different pit and fissure sealants: a 1-year study. Int J Clin Pediatr Dent 2013;6:183-7.

32. Beloica M, Goracci C, Carvalho CA, Radovic I, Margvelashvili M, Vulicevic ZR, et al. Microtensile vs microshear bond strength of all-inone adhesives to unground enamel. J Adhes Dent 2010;12:427-33.

33. Luhrs AK, Guhr S, Schilke R, Borchers L, Geurtsen W, Günay H. Shear bond strength of self-etch adhesives to enamel with additional phosphoric acid etching. Oper Dent 2008;33:155-62.

34. Devarasa GM, Subba Reddy VV, Chaitra NL, Swarna YM. Self-etching adhesive on intact enamel, with and without pre-etching. Microsc Res Tech 2012;75:650-4.

35. Van Meerbeek B, Kanumilli $P$, De Munck J, Van Landuyt K, Lambrechts $P$, Peumans $M$. A randomized controlled study evaluating the effectiveness of a two-step self-etch adhesive with and without selective phosphoric-acid etching of enamel. Dent Mater 2005;21:375-83.

36. Venker DJ, Kuthy RA, Qian F, Kanellis MJ. Twelve-month sealant retention in a school-based program using a self-etching primer/adhesive. J Public Health Dent 2004;64:191-7.

37. Burbridge L, Nugent Z, Deery C. A randomized controlled trial of the effectiveness of a one-step conditioning agent in fissure sealant placement: 12 month results. Eur Arch Paediatr Dent 2007;8:49-54.

38. Yoshida Y, Yoshihara K, Nagaoka N, Hayakawa S, Torii Y, Ogawa $\mathrm{T}$, et al. Self-assembled Nano-layering at the adhesive interface. J Dent Res 2012;91:376-81.

39. Mitra SB, Lee CY, Bui HT, Tantbirojn D, Rusin RP. Long-term adhesion and mechanism of bonding of a paste-liquid resin-modified glassionomer. Dent Mater 2009;25:459-66.

40. Lin A, Mclntyre NS, Davidson RD. Studies on the adhesion of glassionomer cements to dentin. J Dent Res 1992;71:1836-41.

41. Mena-Serrano A, Kose C, De Paula EA, Tay LY, Reis A, Loguercio $A D$, et al. A new universal simplified adhesive: 6-month clinical evaluation. J Esthet Restor Dent 2013;25:55-69.

\section{Six-month clinical evaluation of fissure sealants placed with different adhesive systems: a randomized controlled trial}

\begin{abstract}
OBJECTIVE: To compare the retention and caries formation rates of fissure sealants applied with an etch\&rinse adhesive system (Adper Single Bond 2) or with an universal adhesive system (Single Bond Universal) used with etch\&rinse mode or self-etch mode after 6 months.
\end{abstract}

Materials and Method: Non-invasive fissure sealants of 13 patients (19-22 age) were evaluated. The fissure sealant (Fissurit FX, Voco, Cuxhaven, Germany) was placed after three different pretreatment procedure and then polymerized; Group A: $35 \%$ phosphoric acid gel + Adper Single Bond 2 (3M ESPE, St Paul MN, USA), Group B: 35\% phosphoric acid gel + Single Bond Universal adhesive (3M ESPE, St Paul MN, USA), Group C: Single Bond Universal adhesive. All the materials were used according to the manufacturers' recommendations. A total of 144 teeth were sealed ( $n=48$ in each group). The retention of fissure sealants and caries formation was evaluated by two calibrated examiners at one week and six month recalls. The evaluation criteria for retention were $1=$ full retention, 2=partial loss, $3=$ total loss. Data were analyzed with Pearson chi square test.

RESULTS: The recall rate was $100 \%$ at the 6 -month control. Retention rates at 6-months were as follows: Group A: full retention: $93.75 \%$ and total loss: $6.25 \%$ of the sealants; Group B: all sealants were recorded to exhibit full retention; Group C: full retention: $29.2 \%$, partial loss: $2.1 \%$ and total loss: $68.8 \%$ of the sealants. Differences between Group $\mathrm{C}$ and the other groups were statistically significant $(p<0.001)$. No caries was detected at the 6 -month control.

CONCLUSION: Single Bond Universal adhesive used in a selfetch mode showed a clinically low performance

KEYWORDS: Dental adhesives; dental caries; fissure sealants 